\title{
Erratum to: A Robust MPP Tracker Based on Sliding Mode Control for a Photovoltaic Based Pumping System
}

\author{
Farhat Maissa ${ }^{1,2} \quad$ Oscar Barambones ${ }^{2} \quad$ Sbita Lassaad $^{3} \quad$ Aymen Fleh $^{3}$
}

${ }^{1}$ Department of Electrical, Electronics and Communications Engineering, American University of Ras Al Khaimah, Ras Al Khaimah 10021, UAE

${ }^{2}$ Advanced Control Group, Faculty of Engineering of Vitoria-Gasteiz, University of the Basque Country, Bilbao, Spain

${ }^{3}$ Electrical and Automatic Engineering Department, Engineering School of Gabes, University of Gabes, Zrig, Gabes 6029, Tunisia

Erratum to: Int. J. Autom. Comput. Vol. 14 Issue 4, August 2017, pp 489-500 DOI: 10.1007/s11633-016-0982-6.

Correction: The name of the third author is corrected as Sbita Lassaad which was misspelled as Sbita Lassad in the original version.

The online version of the original article can be found at http://dx.doi.org/10.100 7/s11633-016-0982-6.

\footnotetext{
published online August 24, 2017

(C) Institute of Automation, Chinese Academy of Sciences and Springer-Verlag GmbH Germany 2017 